\title{
Cloud services as the ultimate gate(keeper)

\author{
Björn Lundqvist*
}

\begin{abstract}
In the Internet of Things (IoT), the amount and smart use of data will determine whether or not a firm can compete successfully. Manufacturing firms will collect data through sensors in their devices and, at least in the cases of SMEs, likely store the collected data in the cloud, purchasing cloud services and storage from the large e-platform providers doubling as cloud providers. The e-platform providers will also collect data from users of their other services. These data are often generated by the same firms that purchase cloud services when they use the e-platforms to sell goods and services. Access to the data and to data analytics on fair business terms, and the possibility to switch cloud and service providers are vital for the SMEs and, in general, to create a competitive and vibrant IoT. However, cloud and e-platform customers seem to be facing difficulties. According to the EU Commission, SMEs are finding it particularly hard to engage cloud and e-platform providers, and to gain access to cloud services on reasonable, transparent terms. The contracts are skewed in favour of the cloud providers. The customers get locked in and may be obliged to agree not to assert any of their intellectual property rights vis-à-vis the cloud provider or the cloud provider's network. Moreover, the cloud and e-platform providers may under certain circumstances access and make use of the users' data, and that may give them a competitive advantage vis-à-vis the users, since the providers may have access to much more data, even data originating from the users' competitors, suppliers, customers, etc. They can thus use all the data available to them to obtain a fuller picture of whole industries, and they may use that advantage in data to leverage and enter users' markets. Indeed, they may use the data in the cloud for data-driven business strategies to enter the core market of the firms that have provided them with data in the first place. This article discusses whether competition law can address the conduct of the cloud and e-platform providers, so that firms may access and make use of all the possibilities that the IoT harbours.

KEYWORDS : digital economy, the cloud, interoperability, the Internet of Things, industrial internet, competition law, antitrust, big data, privacy, data protection, platforms, ecosystem

JEL CLASSIFICATIONS: K00, K20, K21, K31, K42, L11, L14, L22, L23, L24, L41, L42
\end{abstract}

* Björn Lundqvist is an Associate Professor, Stockholm University. E-mail: bjorn.lundqvist@juridicum.su.se

(C) The Author(s) 2019. Published by Oxford University Press. All rights reserved.

For permissions, please e-mail: journals.permissions@oup.com 


\section{INTRODUCTION}

In the Internet of Things (IoT), more products, devices and technologies will be connected to the internet. This means that data, personal or non-personal, will increasingly be collected, stored, distributed, and re-used on a grand scale.

A new 'feature' of the IoT is that firms active in the old economy will produce their products with added sensors to monitor and collect data. Device producers, regular brick-and-mortar firms, whether SMEs or large firms, will collect data. They might obtain their own data storage and analytics tools, but it is likely that many of them will purchase such services from e-platforms or cloud providers.

While data may be covered by copyright, protected under the sui generis database right, or may be considered trade secrets, and personal data falls under the data protection regulations, ${ }^{1}$ most non-personal data gathered by devices will not be covered by any sort of property rights. ${ }^{2}$ Indeed, in theory, the non-personal data is 'free,' while access to the data may still be restricted, contractually or by technical means, eg the data may have been encrypted by the firm collecting the data. ${ }^{4}$

Several tech firms, or internet intermediates, such as Amazon, Google, and Microsoft, provide cloud space, and the market for cloud services is growing due in

1 See, for example, Regulation (EU) 2016/679 of the European Parliament and of the Council of 27 April 2016 on the protection of natural persons with regard to the processing of personal data and on the free movement of such data, and repealing Directive 95/46/EC (GDPR), Text with EEA relevance, OJL 119, 4 May 2016, 1-88.

2 The data collected will be valuable. Indeed, the global flow of data is already worth more than the international trade of goods. European Commission, Commission Staff Working Document on the free flow of data and emerging issues of the European data economy, $\operatorname{COM(2017)~} 9$ Final, 10 January 2017.

3 From a civil law perspective, if data is not covered by property rights and a firm has legitimate access to the data, generally, the firm should be able to make use of it without the need for a licence. Indeed, that would be the consequence of the data not being covered by a property right. The foremost German discussion regarding whether to create a property right for non-personal data originates from this perspective, cf. Herbert Zech, 'Information as a Tradable Commodity', in De Franceschi (ed), European Contract Law and the Digital Single Market (intersentia 2016) 51-79; Wolfgang Kerber, 'A New (Intellectual) Property Right for Non-Personal Data? An Economic Analysis' [2016] GRUR Int, 989; Josef Drexl, 'Designing Competitive Markets for Industrial Data - Between Propertisation and Access' (31 October 2016), Max Planck Institute for Innovation \& Competition Research Paper, No 16-13, 18. Available at SSRN: < https:// ssrn.com/abstract=2862975 > or <http://dx.doi.org/10.2139/ssrn.2862975> (accessed 23 July 2018).

4 Access to data may be given in confidence or, rather, under an agreement that explicitly or implicitly stipulates certain restrictive covenants for what the firm holding the data may do with it. Accessing and making use of the data in breach of such implicit or explicit covenant may imply breach of contract. Moreover, if the access or use takes place in certain jurisdictions, such as the UK, the law of confidence may impose on a party a duty not to disclose information in breach of confidence. Potentially, the UK law of confidence goes further, requiring the party to observe the broad principle of equity that he who has received information in confidence shall not take unfair advantage of it. See UK case Seager v Copydex Ltd [1967] 2 All ER 415, 417 per Lord Denning. The case law on this point is, however, according to Chris Reed and Alan Cunningham, unhelpful in cloud cases because the alleged breaches in those cases have all fallen into three classes: disclosure to a third party; use of the information to compete with the confider; or use to make a profit which could have been made by the confider. The cloud computing service provider's activities in creating and exploiting user information fall into none of these, according to Chris Reed and Alan Cunningham, other than by accident. Chris Reed and Alan Cunningham, 'Ownership of Information in Clouds' in Christopher Millard (ed), Cloud Computing Law (OUP 2013) 151. Moreover, whether such a broad doctrine of equity would apply generally, eg in civil law jurisdictions, is highly contentious. 
part to the data storage required by the $\mathrm{IoT}^{5}$ Firms that provide services through eplatforms, including cloud providers, have access not only to their own collected data. They may also, depending on the stipulations in their contracts, have access to, and the right to use, data from their customers for commercial purposes.

Given that access to data might reflect market power, this article will address, firstly, whether e-platforms and cloud providers should be considered holding market power when controlling large volumes of data, especially when having the right to access and use their customers' data.

Because they are the nodes in the exchange of data, the current set-up seems to benefit the system leaders - the gatekeepers - in the virtual ecosystems being developed around their clouds, their e-platforms and 'silos'. The large providers not only collect large amounts of data, through their e-platforms and digital services, be they social sites, general search sites, music services, market or auction platforms, etc.; they may also obtain data from the data storage services they provide.

It seems that the gatekeepers in the digital economy are taking on the roles of data storage suppliers and analytics service providers for brick-and-mortar firms, thanks to being cloud service providers and system leaders in e-ecosystems. They provide three main cloud services that can be overlapping: Infrastructure as a Service (IaaS), Platform as a Service (PaaS), and Software as a Service (SaaS). The three services represent different layers in the cloud, and they imply different service complexity and different requirements for the parties, including for when the provider needs to access data from the customer. ${ }^{6}$

The standard service agreements offered by the providers to their customers are often skewed to the benefit of the providers, while the customers may be obliged to provide data and can be both contractually and technically locked in with their service provider. For example, there is evidence that platform customer service agreements, including cloud service agreements, do not include information on termination of contract, ${ }^{7}$

5 For an comprehensive but somewhat outdated list of clouds and cloud providers; see Simon Bradshaw, Christopher Millard and Ian Walden 'Contracts for Clouds: Comparison and Analysis of the Terms and Conditions of Cloud Computing Services', Queen Mary School of Law Legal Studies Research Paper No 63/2010, 15, SSRN:<https://ssrn.com/abstract=1662374>or $<$ http://dx.doi.org/10.2139/ ssrn.1662374> accessed 24 July 2018. See also Bob Evans, 'The Top 5 Cloud-Computing Vendors: \#1 Microsoft, \#2 Amazon, \#3 IBM, \#4 Salesforce, \#5 SAP', Fobes, 7 Nov 2017. <https://www.forbes.com/ sites/bobevans1/2017/11/07/the-top-5-cloud-computing-vendors-1-microsoft-2-amazon-3-ibm-4-sales force-5-sap/\#a072bd76f2eb > accessed 23 July 2018.

See also PR News Service, Vision, 'The Cloud Storage Market Size Is Expected To Grow from USD 30.70 billion in 2017 to USD 88.91 billion by 2022, at a Compound Annual Growth Rate (CAGR) of 23.7 per cent' <https://www.prnewswire.com/news-releases/the-cloud-storage-market-size-is-expectedto-grow-from-usd-3070-billion-in-2017-to-usd-8891-billion-by-2022-at-a-compound-annual-growth-ratecagr-of-237-300597852.html> accessed 23 July 2018.

6 See generally, W Kuan Hon and Christopher Millard, 'Cloud Technologies and Services' in Christopher Millard (ed) Cloud Computing Law (OUP 2013).

7 European Commission, Commission Staff Working Document Impact Assessment, Accompanying the document Proposal for a Regulation of the European Parliament and of the Council on a framework for the free flow of non-personal data in the European Union, SWD/2017/0304 final-2017/0228 (COD), Brussels, 13 September 2017 (Impact Assessment), 10 et seq. In reference to cloud services provided for free cf. Bradshaw, Millard and Walden (n 5). 
contractual rights and information regarding porting data, ${ }^{8}$ but may include clauses regarding non-assertion and non-reverse engineering greatly benefitting the cloud provider which can gain data from the industry. ${ }^{9}$ Moreover, as hinted at above, the contracts may also give the e-platform provider the right to use its customers' data for its own commercial benefits. ${ }^{10}$

8 There is no coherent technical standard that facilitates the transfer of data between clouds. Porting data from one cloud provider to another can be hindered both by the exit rules stipulated in the contracts and by the fact that it is difficult and costly to transfer data. Cf. European Commission, ibid 10. See also W Kuan Hon, Christopher Millard and Ian Walden, 'Negotiated Contracts for Cloud Services' in Christopher Millard (ed), Cloud Computing Law (OUP 2013) 95 et seq. W Kuan Hon, Christopher Millard and Ian Walden, state:

$[\mathrm{m}]$ any cloud users cited lock-in as one of their top concerns. Lock-in involves several aspects. Exit strategy and end-of-contract transition were major user concerns, including data portability; retaining metadata as well as data was considered important. Users were wary of being 'locked in' for too long an initial contract term. This issue [...] is often pricing-related, and sometimes negotiable. A major lock-in concern is risk of (over-)dependence on one provider's, often proprietary, service. As cloud use becomes more widespread and sophisticated, we believe contracts may extend beyond addressing data portability to cover application portability, VM portability, and perhaps even interoperability.

9 'Beware the IP non-assert clause in AWS cloud service agreement, warns ex-Microsoft patent chief, 12 July 2015, iam-media <http://www.iam-media.com/blog/detail.aspx?g=16404f83-82a0-4a0f-bc7938ba53ceaf2d> accessed 10 May 2018. See also Jaydip Sen, 'Security and Privacy Issues in Cloud Computing' in Antonio Ruiz-Martínez, Fernando Pereñíguez-García and Rafael Marín-López (eds), Architectures and Protocols for Secure Information Technology Infrastructure (IGI-Global 2013) 16 et seq, discussing the Amazon cloud service contracts, where the non-assert clause required the customer to not assert, by itself or through others, any IP claims regarding the AWS services it has used. The clause applied, without any time limit, after the agreement had ended, and could be said to amount to a patent no-challenge clause, See also Tom Krazit (14 July 2017), 'Amazon Web Services adds IP protection while dropping controversial patent clause from user agreement.' It seems that Amazon has dropped its controversial non-assert clause, however the indemnification (s 9.2 of the cloud service contract, cf. <https://aws.amazon.com/agreement/ > last accessed 12 September 2018) could still be interpreted as shielding Amazon and others in its ecosystem from infringement damages suits. <https://www.geekwire.com/2017/amazon-web-services-added-ip-protec tion-dropping-controversial-patent-clause-user-agreement/> last accessed 12 September 2018. See also Richard Kempe (9 June 2017), 'Growing Patent Claim Risks in Cloud Computing' < http://www.kempitlaw. com/growing-patent-claim-risks-in-cloud-computing/> last accessed 12 September 2018.

10 According to Michael R Overly and Matthew A Karlyn:

$[\mathrm{m}]$ any cloud computing providers want to analyze and use the customer data that resides on their servers for their own commercial benefit; in particular, they are interested in the data customers create as they use the services. For example, the provider may wish to use the customer's data, aggregated along with other customers' data, to provide data analysis to industry groups or marketers.

Michael R Overly and Matthew A Karlyn, Guide to IT Contracting (Auerbach Publications 2012) 78 et seq. See also Michael R Overly, 'The provider may suggest that it will limit its use to de-identified customer data, and that such use is similar to Internet "cookies" that follow where a user goes and what a user does.' Michael R Overly, 'Drafting and Negotiating Effective Cloud Computing Agreements' (2015) Lexis Practice Advisor Journal < https://www.lexisnexis.com/lexis-practice-advisor/the-journal/ $\mathrm{b} / \mathrm{lpa} /$ archive/2015/11/30/drafting-and-negotiating-effective-cloud-computing-agreements.aspx $>$ accessed 29 July 2018 . Overly have in a separate article stated that: '[m] ost cloud agreements include the right for the vendor to use aggregated data. While this may be entirely acceptable to many customers, the problem is that the term "aggregated" is seldom defined or, at best, it includes a vague reference to not identifying the customer.' cf. Michael R Overly, 'Crossroads of Cybersecurity and the Law' (2017) CSO <https://www.csoonline.com/article/3217724/cloud-security/what-can-my-cloud-pro vider-do-with-my-data.html $>$ accessed 24 July 2018. According to W Kuan Hon, Christopher Millard 
The article will, secondly address certain terms and conditions that may be included in the cloud service agreements and whether they may constitute a violation of EU competition law, focusing on the application of Article 102 TFEU.

However, not only could the terms and conditions of the cloud service agreements and technical barriers for transferring data be anticompetitive, the general set-up of having cloud providers lock in customers and gain access to customer data could also cause antitrust harm. If the internet intermediates doubling as cloud providers can contractually lock in their brick-and-mortar customers (their users) to transfer data to them, they may soon hold much of the data collected by devices in the IoT.

There is also a form of discrimination and leveraging in the services provided by the system leaders. While a provider has access to, and a right to use, all the data in the eecosystem connected to its platform and cloud, the individual brick-and-mortar user has access only to its own data. ${ }^{11}$ The data accessible to the provider can be from customers, suppliers, and even from competitors of the individual user. That implies an advantage in knowledge that may be used if the provider decides to enter the market of the user.

Of course, the cloud provider can be contractually restricted only to use the customers' data, for example, in order to provide the cloud service. Currently, this seems to be a common term related to data ownership and use, included in the cloud service agreements of several large cloud providers. ${ }^{12}$ However, commentators indicate that cloud providers may have the contractual right to access and use customer's data. ${ }^{13}$ In particular, when the cloud service provided includes a more complex collaboration, eg SaaS, the provider may need to access data in an uncorrupted fashion to be able to provide the software service contracted with the user. ${ }^{14}$

According to Bradshaw, Millard, and Walden, it is primarily 'free' cloud services that may impose non-monetary costs on the customer (including business customers), such as contextual advertising or the imposition of licence terms that allow a provider to re-use the customers' data for its own purposes. ${ }^{15}$

and Ian Walden, 'The Problem Of "Personal Data" In Cloud Computing: What Information Is Regulated?-The Cloud Of Unknowing' (2011) 1 Int Data Priv L 211-28: '[m] any SaaS services go beyond "pure" storage. Providers may access stored unencrypted personal data (for example, to run advertisements against content)....

11 In reference to personal data, the cloud provider must gain consent to be able to access and analyse personal data from a data client. Cf. GDPR and WP29 2012.

12 It seems that several of the larger cloud providers, eg Amazon and Google, in the current standard contracts state that they will only access customer data to develop the service given. However, it may depend on the cloud service. Cf. (n 18) below regarding the service Google Docs/Drive.

13 See (n 10). See also discussion below.

14 According to Hon, Millard and Walden (n 10).

15 Bradshaw, Millard and Walden (n 5). See also the critique against Google for a contract clause giving Google the right to use the user's data for the cloud service Google Drive/Docs, mainly catering to persons and SMEs. For example, Zack Whittaker, 'Who Owns Your Files On Google Drive? Google Drive's Terms Of Service Do Indeed Allow You To Own Your Own Files, But Grant The Company A License To Do As It Wants With Your Uploaded Content', CNET, April 24, 2012. The clause read:

Your Content in our Services: When you upload or otherwise submit content to our Services, you give Google (and those we work with) a worldwide licence to use, host, store, reproduce, modify, create derivative works (such as those resulting from translations, adaptations or other changes that we make so that your content works better with our Services), communicate, 
Furthermore, it seems that a cloud provider may conduct so-called 'data mining', without running the risk of violating the cloud customers' copyright, trade secret or database rights. ${ }^{16}$ The gatekeeper can then combine the results of the data mining with data obtained through its own services. ${ }^{17}$

Thus, a platform or a cloud provider having access and right to use its customers data may be able to obtain a fuller picture of whole industries because it is able to access the data from all or several participants in those industries. ${ }^{18}$ This would enable it not only to succeed on its own core markets, but also to leverage that data superiority so as to integrate onto the core markets of the brick-and-mortar firms. Physicaldigital giants created through mergers like that of Amazon and Whole Foods, and partnerships like Walmart and Google, should possibly be viewed through this lens. For example, Amazon's advantage in retail data might have given it an incentive to integrate downstream to physical retail by purchasing Whole Foods. ${ }^{19}$

If a provider holds the data for certain brick-and-mortar markets, combines that with its own data, and has the best analytical tools for predictive modelling, it will be able to predict and (hyper-)nudge the consumers as regards what device to buy, before a device producer is able to do so. With the infusion of a data-driven business model, it would be able to transform the old economy device market to a network

publish, publicly perform, publicly display and distribute such content. The rights that you grant in this licence are for the limited purpose of operating, promoting and improving our Services, and to develop new ones. This licence continues even if you stop using our Services (for example, for a business listing that you have added to Google Maps).

16 Reed and Cunningham (n 4) 151 et seq. and 161 et seq.

17 Chris Reed and Alan Cunningham give a hypothetical example: a service provider with a number of motor insurers as customers could mine their data to extract information on the accident rates and types for different makes and models of vehicle. Reed and Cunningham (n 4) 161.

18 Interestingly, the Commission in the proposed platform to business (P2B) regulation (which does not cover cloud services) has somewhat grasped this problem and drafted an Art 7 which obliges providers of online intermediation services to provide business users with a clear description of the scope, nature and conditions of their access to and use of certain categories of data. The description should be proportionate and might refer to general access conditions, rather than an exhaustive identification of actual data, or categories of data, in order to enable business users to understand whether they can use the data they have created with the provider of the online intermediation services, or not. Indeed, the provider of the online intermediation services is not obliged to give the customer (the business user) access to the data the user creates through his business on the platform. The provider is only required to inform a business user whether it has 'access to personal data or other data, or both, provided by that business user in connection to his or her use of the online intermediation services concerned or generated through the provision of those services to that business user and the consumers of his or her goods or services, and if so, to which categories of such data and under what conditions; and whether, a business user has access to personal data or other data, or both, including in aggregated form, provided by or generated through the provision of the online intermediation services to all of the business users and consumers thereof, and if so, to which categories of such data and under what conditions'. Moreover, the proposed Art 6 of the P2B regulation states that providers need to be transparent if they were to discriminate in reference to access to data that the provider holds. Cf. the proposed P2B regulation: Brussels, 26 April 2018 COM(2018) 238 final 2018/0112 (COD) Proposal for a regulation on promoting fairness and transparency for business users of online intermediation services.

19 Cf. Greg Petro, 'Amazon's Acquisition Of Whole Foods Is About Two Things: Data And Product', Forbes, 2 August 2017 <https://www.forbes.com/sites/gregpetro/2017/08/02/amazons-acquisition-ofwhole-foods-is-about-two-things-data-and-product/\#3f4ef8fa8084> accessed 20 May 2018. 
data-driven market that is likely to tip in its favour. ${ }^{20}$ The internet intermediates could thus in such cases leverage their control over the data to become monopolists in regard to the product or service market. In academia and the public debate, many people see risks with so much data being held by just a few firms; this could imply holding power. However, general leveraging abuses could also be triggered when the cloud providers enter neighbouring markets based on superior data. ${ }^{21}$

This article will thus, thirdly and lastly, address the issue of whether the collection of data by the e-ecosystem leaders doubling as cloud providers and their subsequent use of the data might be problematic and constitute a violation of Article 102 TFEU, as abusively leveraging market power.

The issues addressed in this article are located at the interface between IoT, cloud computing and competition law, and the interface has not previously been addressed in a comprehensive way from an antitrust law perspective. ${ }^{22}$ This article intends to fill that void, and to analyse the cloud business strategy from a competition law perspective in an IoT setting. It should be acknowledged that researchers of cloud computing have in an comprehensive way addressed the terms and conditions of cloud service agreements, ${ }^{23}$ however they have not focused on the interface discussed here, or on the competition law issues raised in this article.

The article is divided into four parts. First, the article will raise issues and questions regarding the antitrust harms and the problems with internet intermediates collecting data through their own services and as cloud service providers. This part will describe the cloud providers' market power and business conduct. In the second and third parts, the article will address whether general competition law is applicable to the issues at hand. These parts also, to a lesser extent, analyse the sector-specific regulations now being developed in this area. In the fourth part, the article is concluded.

\section{IDENTIFICATION OF THE PROBLEM}

\section{Market Power}

It is increasingly acknowledged that data collection is key in the ability of firms to gain and hold market power. ${ }^{24}$ The market power obtained by the access to or the

20 Jens Prüfer and C Schottmüller, Competing with Big Data (CentER Discussion Paper; vol 2017-007), CentER, Center for Economic Research, Tilburg.

21 See generally for the background purposes, Maurice Stucke and Allen Grunes, Big Data and Competition Policy (1st edn, OUP 2016); Ariel Ezrachi and Maurice Stucke, Virtual Competition: The Promise and Perils of the Algorithm-Driven Economy. Mark Patterson, Antitrust Law in the New Economy: Google, Yelp, LIBOR, and the Control of Information (Harvard University Press 2016).

22 See however Ian Walden and Laise Bornico, 'Ensuring competition in the Clouds: The role of Competition law?', ERA Forum (2011) 12; Tim Cowen and Annabelle Gawer, 'Competition in the Cloud: Unleashing Investment and Innovation Within and Across Platforms' (2012) 85 Digi Econ J 45.

23 See for example Reed and Cunningham (n 4) 161. Bradshaw, Millard and Walden (n 5). See also text connected with fn 4 supra.

24 See, for example, Wolfgang Kerber, 'Digital Markets, Data, and Privacy: Competition Law, Consumer Law, and Data Protection', MAGKS, Joint Discussion Paper Series in Economics (No 14-2016). Available at SSRN: <http://ssrn.com/abstract=2770479 or http://dx.doi.org/10.2139/ssrn.2770479> accessed 12 December 2017, 3 et seq. There are several authors who purport that holding big data does not equate market power. Generally, they argue that big data does not create a significant barrier to entry and they base their claims, inter alia, on the non-exclusive and non-rivalrous nature of data and a claimed ease of collecting it, while disregarding many potential entry barriers. Other scholars argue that the harm 
holding of vast amounts of data, ${ }^{25}$ connected to software for predictive modelling, creates barriers to entry for second movers. Further, the market for providing services based on data may change due to network effects resulting from the data-driven business strategies of the first movers. ${ }^{26}$ The amounts of data collected increase service quality, which in turn attracts more users. ${ }^{27}$ The German Competition Act has recently been amended to reflect this, now stating that 'access to relevant data is a potential source of market power. ${ }^{28}$

Moreover, predictive modelling needs to work fast to identify current and future trends: 'nowcasting.' Nowcasting is the capacity of a company to use the velocity at which a dataset grows to discern trends before others do. Nowcasting enables a firm not only to track trends in users' conduct in real time, but also to monitor trends in (potential) competitors' conduct, and to respond more quickly, which helps it push or nudge the market. ${ }^{29}$

Leading internet intermediates, which also act as cloud providers, collect vast amounts of data, and may have access and the right to use to other firms' data through the cloud. This would, under certain situations, give these firms much leverage in knowledge. ${ }^{30}$ Based on the advantage in data, they can presumably act, both on the data market and on the connected product or service market, independently

created by big data pertains mainly to privacy. However, these conclusions are based on the limited existing economic studies on big data, which often focus on one specific market (most commonly on search engines or personal data markets). Daniel L Rubinfeld and Michal Gal, 'Access Barriers to Big Data' (2017) 59 Arizona L R 339. Available at SSRN: <https://ssrn.com/abstract $=2830586>$ or $<$ http://dx. doi.org/10.2139/ssrn.2830586> accessed 12 December 2017. See, for example, Darren S Tucker and Hill Wellford, 'Big Mistakes Regarding Big Data' (2014) 6 Antitru Src. See also Maureen K Ohlhausen and Alexander P Okuliar, 'Competition, Consumer Protection, and the Right [Approach] To Privacy' (2015) 80 Antitrust L J 121; James C Cooper, 'Privacy and Antitrust: Underpants Gnomes, the First Amendment, and Subjectivity' (2013) 20 George Mason L Rev 1129.

25 There is a discussion regarding the definition of 'data': does it encompass syntactic information, semantic information, or both, and where should one draw the line in reference to protecting 'data'? See Drexl (n 3) 12 et seq. Available at SSRN: <https://ssrn.com/abstract=2862975 $>$ or $<$ http://dx.doi.org/10. 2139/ssrn.2862975 > accessed 2 December 2017. See also Andreas Wiebe, 'Protection of industrial data - a new property right for the digital economy?' (2017) 12 J Intell Prop L Prac 62-71, $67<$ https://doi. org/10.1093/jiplp/jpw175> (accessed 2 December 2017).

26 ibid. See also OECD (2016), Big Data-Bringing Competition Policy to the Digital Era. <http://www. oecd.org/daf/competition/big-data-bringing-competition-policy-to-the-digital-era.htm $>$ accessed 2 December 2017; Autorité de la Concurrence and Bundeskartellamt (2016), Competition Law and Data <http://www.autoritedelaconcurrence.fr/doc/reportcompetitionlawanddatafinal.pdf $>7,10$ et seq. accessed 2 December 2017.

27 Rubinfeld and Gal (n 24).

28 ARCs 18 para 2(a) now clarifies that a 'market' - infar as this term is used within competition law-can also exist where products and/or services are provided free of charge. This clarification followed an initiative by the FCO to better understand and tackle competition issues in digital markets, which led to the publication of a Working Paper on 'Market Power of Platforms and Networks' in June 2016. Consequently, ARCs 18 para 3(a) now provides certain specifications on the assessment of market power with respect to multi-sided markets and networks, listing, among other things, network effects and access to market relevant data. NortonRose, Fullbright, German Competition Law update: New revised act against restraints of competition entered into force <http://www.nortonrosefulbright.com/knowledge/ publications/155186/german-competition-law-update-new-revised-act-against-restraints-of-competitionentered-into-force $>$ accessed 31 December 2017. 
and self-assuredly knowing that they hold an advantage in knowledge in relation to their competitors, customers, and consumers. This is particularly true in the situation where the cloud provider has access to the data collected by all firms on a market, while the firms active on the market only have access to their own data. In such cases, the platform or cloud providers could be considered to have market power. Given the importance of data and information on the market for data, upstream in relation to the product market, the provider, if no contractual or legal restrictions are available, could even be considered dominant. It is very difficult to measure dominance, but there are famous competition law cases where the ECJ has identified upstream 'markets' for licensing intellectual property rights, and, hence, dominant positions for the rights holders, even though no licence had been granted. ${ }^{31}$ Such lines of reasoning may be used for identifying data markets and market power on such markets. As discussed below, holders of large datasets reflecting data from all firms active on a product market could reflect market power on the upstream data market connected to that product market.

However, could large datasets combined with data-driven business conduct lead not only to market power, but also to antitrust harm, or should data collection and mining be considered regular competition on the merits?

As discussed below, the conduct of internet intermediates and cloud providers may be considered anticompetitive. A general applicable theory of antitrust harm could be that they are leveraging market power inherent in the data so as to exclude equal efficient competitors on connected data-driven (downstream or neighbouring) markets; or/and that the cloud providers contractually or technically lock in a firm so as to cut off that firm from the cloud provider's rivals, eg other cloud providers. Such conduct may cause antitrust harm. There are thus, depending on how you divide them, two or three general theories of antitrust harm that may apply to the internet intermediates. ${ }^{32}$

\section{Leveraging market power inherent in data}

The economists Prüfer and Schottmüller have in a recent article ${ }^{33}$ identified that data-driven markets tend to tip even from slight differences in the amount and quality of data, and when such a market tips there is no remedy to re-establish competition except granting access to data. Moreover, they also showed that superiority in data on one market may be leveraged to create market dominance on neighbouring markets, should a data-driven business model be implemented.

Several economists point to the fact that direct and indirect network effects have become relevant because of recent progress in data storage and data analytics

31 For example, C-418/01, IMS Health v NDC Health, ECLI:EU:C:2004:257, paras 42 et seq.

32 In addition to these theories, new innovative legal and economic concepts and methodology could be discussed. For example, the notions of privacy, dignity, self-determination, and personal autonomy could be used to identify new forms of antitrust harm. However, these new innovative forms of antitrust harm will not be discussed in this article.

33 Prüfer and Schottmüller (n 20). See also the CASE AT.39740 Google Search (Shopping), 27/06/2017 and European Commission (n 7); European Commission (n 2). 
technologies. ${ }^{34}$ In contrast to direct network effects and dynamic economies of scale (learning curve effects), data-driven indirect network effects cannot easily be copied by competitors or eliminated by innovation or new technology. ${ }^{35}$ With initial differences in amount and quality of data, a market plagued by indirect network effects will eventually tip and one firm will dominate the market. An important feature of a tipped market is that there are very few incentives for either the dominant firm or the ousted firms to further invest in innovation. The reason is that, in the stable steady state where one firm has virtually no demand and the other firm has virtually full demand, the ousted firm knows that the dominant firm both offers consumers a significantly higher quality level and has significantly lower marginal costs of innovation. ${ }^{36}$ When a market has tipped due to data-driven indirect network effects, new firms are deterred from entry, even if they have developed revolutionary technology, ie a disruptive innovation. ${ }^{37}$ Indeed, when this has occurred and a firm is in a monopoly or quasi-monopoly position, it could be declared that the market or the industry is failing. ${ }^{38}$ The market cannot by itself create competition. This could, in turn, according to several economists, imply that competition law should be applicable and used to facilitate a functional market. ${ }^{39}$ However, that would imply using competition law early in the competitive process, before the market has tipped.

Going a step further, economists also argue that a dominant position in one datadriven market could be used to gain a dominant position in another market that is not (initially) data-driven. If market entry costs are not prohibitive, a firm that holds much relevant data and manages to find a 'data-driven' business model can dominate virtually any market in the long term. Consequently, if internet intermediates realize that the data they hold constitute a key input to the production of quality on a market, they will most likely enter that market and moreover continue to enter neighbouring markets, even if these are old economy device markets. ${ }^{40}$ The IoT and the infusion of data-driven business models transform such markets into network-driven ones that are likely to tip in favour of one firm. This suggests a domino effect: a first mover in data can obtain dominance in data and leverage its competitive edge in data to a dominant position in neighbouring markets. This can lead to tipping of neighbouring markets, even when these markets are "old economy" and already

Wolfgang Kerber and Jonas Frank, 'Data Governance Regimes in the Digital Economy: The Example of Connected Cars' (3 November 2017). <https://ssrn.com/abstract=3064794> or <http://dx.doi.org/ 10.2139/ssrn.3064794> accessed 2 January 2018. See also Monopolkommission (2015), 'Competition Policy: The Challenge Of Digital Markets', Special Report No 68. Lianos and Motchenkova show that a dominant monopoly platform results in higher prices and underinvestment in quality-improving innovations by a search engine, relative to what would be optimal for society. More generally, they show that monopoly is sub-optimal because of harm to advertisers in the form of high prices, harm to users in the form of reduced quality in search results, and harm to society in the form of lower innovation rates in the industry. Ioannis Lianos and Evgenia Motchenkova, 'Market Dominance and Search Quality in Search Engine Market' (2013) 9 J Compet L Econ 419-55, 419, 451.

35 Prüfer and Schottmüller (n 20).

36 ibid.

37 ibid.

38 Kerber and Frank (n 34).

39 ibid.

40 Prüfer and Schottmüller (n 20). 
served by traditional brick-and-mortar firms. This would create failed markets where no competition takes place.

As discussed below, if the data-driven business model and indirect effects cause market failure, due to the leveraging of an advantage in data, and thus market power, from one market to a neighbouring market, such conduct may perhaps be considered abuse under Article 102 TFEU. This depends on the conduct of the firm leveraging. Is the conduct outside the notion of competition on the merits, and does it cause anticompetitive effects?

An example of the transformation under data-driven business models would be the car industry, where data are currently being collected from new cars and their drivers through applications and monitors. Such data are mainly collected by car manufacturers, but also other forms of apps may today be downloaded to cars and can monitor both car and driver. The paradigm shift due to the amount of data collected may cause the car industry to become data-driven, where the firm holding the most and 'best' data with the best tools for analytics may understand how to produce the 'best' car; depending what firm holds the data, the successful firm in this regard may not be a current car manufacturer. ${ }^{41}$ Indeed, several new manufacturers of cars focusing on, inter alia, data collection seem to be entering the industry. ${ }^{42}$

A further example of the paradigm shift that data and data-driven business model can cause in old industries is from the health sector. In the health sector, several firms hold different forms of data. There are clinical (patient) data, normally held by physician and hospitals, and clinical trial data held pharmaceutical firms. The pharmaceutical firms also hold early R\&D data. We have public health authorities, insurance companies and specific health data firms (eg IMS Health) holding data regarding cost and consumption of pharmaceuticals. Now, digital intermediates, like Google, and specific vertical medical Internet services providers hold much data about patient behaviour, fears and conduct based on data collected on the internet. However, with the introduction of IoT, clothes, watches, bathrooms, etc, will also collect health data from individuals. This will boost the amount and quality of the data collected, and the data will be collected by the device producers and stored in clouds, possibly provided by internet intermediates. The health data could be used to invent or create the health solutions of the future. The health solutions of the future do not necessarily have to be drug- or biotech-based. While drugs can be personalized through personal data, health can also be monitored and controlled through data collection. ${ }^{43}$ Indeed, health is monitored and controlled rather than being treated. Given the introduction of IoT, there will be several firms holding health data, while it is quite obvious that health solutions would benefit from this data being

41 Michele Bertoncello et al., 'Monetizing Car Data New Service Business Opportunities To Create New Customer Benefits' Advanced Industries, McKinsey Report, September 2016 <https://www.mckinsey. $\mathrm{com} /$ /media/McKinsey/Industries/Automotive\%20and\%20Assembly/Our\%20Insights/Monetizing $\% 20$ car\%20data/Monetizing-car-data.ashx $>$ accessed 23 July 2018.

42 See for example the Google self-driving car project Waymo <https://www.google.com/selfdrivingcar/> accessed 24 July 2018.

43 Kevin Cyr, 'Forecasting the Future of Personalized Medicine' <https://medium.com/healthfurther/fore casting-the-future-of-personalized-medicine-c88bc55bb668> accessed 25 May 2018. 
pooled in one place to enable the best data analytics. ${ }^{44}$ Nonetheless, a single firm, for example an internet intermediate and cloud provider, may obtain more and better health data, and be able to use this quality difference to enter the general market of inventing or creating the personalized health solutions of the future. Possibly, it would even be able to tip the market and gain monopoly power through network effects. $^{45}$

A remedy for the structural changes caused by data-driven indirect network effects and tipping is to create something akin to a 'data commons' ie making non-personal data available to everyone, or at least promoting brick-and-mortar firms to pool their data in data pools. ${ }^{46}$ Indeed, the European Commission has suggested that 'data commons' should be created for certain sectors for public policy reasons, and health is one of them. ${ }^{47}$ This would entail forced sharing of harmonized data between competitors and other firms. Several authors implicitly suggest this remedy for the business conduct of internet intermediates like Google. ${ }^{48}$ Moreover, they argue that the incentive for the dominant firm, or other firms, to innovate is not lessened by forced sharing of data. ${ }^{49}$

The creation of a 'data commons' where all parties, including competitors, are obliged to share data, is implicitly a property rule, establishing that information in digital format under certain circumstances is a public good. Such a fundamental shift in how to address data and the digital economy might become necessary, should a data-driven market tip. Data commons might then be the only way to re-establish

44 The GDPR may restrict the possibilities for pooling personal data, especially high risk data such as patient data, and the firms should be cautious with what they may pool in these cases. Regulation (EU) 2016/ 679 of the European Parliament and of the Council of 27 April 2016 on the protection of natural persons with regard to the processing of personal data and on the free movement of such data, and repealing Directive 95/46/EC (GDPR) (n 1).

45 Perhaps this seems unrealistic now, but pooling all that knowledge to one platform could provide many benefits as well as entail a high risk. If the data collected could instead be pooled and combined in a data commons by the pharmaceutical firms or the intermediates, that might prove very useful in the fight against all kinds of diseases. It may substantially decrease the time needed for identifying outbreaks of diseases, for developing new drugs, for understanding the impact of new drugs, side effects, etc. Indeed, data-driven business models may be very successful in the pharma/biotech sector, and, thus, create a need and give rise to benefits of pooling large quantities of data from many sources. See, for example, Peter Groves et al., “The Big Data” Revolution in Healthcare', January 2013, McKinsey <https://www. mckinsey.com/ /media/mckinsey/industries/healthcare\%20systems\%20and\%20services/our \%20insights/the\%20big\%20data\%20revolution\%20in\%20us\%20health\%20care/the_big_data_revolu tion_in_healthcare.ashx $>$ accessed 15 April 2018. See also David Champagne, Amy Hung and Olivier Leclerc, The Road To Digital Success In Pharma (McKinsey \& C0 2015) < https://www.mckinsey.com/in dustries/pharmaceuticals-and-medical-products/our-insights/the-road-to-digital-success-in-pharma $>$ accessed 15 April 2018.

46 Björn Lundqvist, 'Competition and Data Pools' (2018) 7 Journal of European Consumer and Market Law 146-154.

47 EC (2017a), Communication 'Building a European Data Economy', 12. Drexl mentions several legal initiatives, see Drexl (n 25). See also Björn Lundqvist, 'Standardization for the Digital Economy: The Issue of Interoperability and Access Under Competition Law' (2017) 62 Antitrust Bull 710-25; and Björn Lundqvist, 'Big Data, Open Data, Privacy Regulations, Intellectual Property and Competition Law in an Internet of Things World' (29 December 2016). Faculty of Law, Stockholm University Research Paper No 1. Available at SSRN: <https://ssrn.com/abstract=2891484> accessed 15 April 2018.

48 Prüfer and Schottmüller (n. 20), 4 and 32 et seq, providing the example of Google Maps. See also Lianos and Motchenkova (n 34). See also Benjamin Edelman, 'Does Google Leverage Market Power though Tying and Bundling?' (2013) $11 \mathrm{~J}$ Compet L Econ 365-400.

Prüfer and Schottmüller (n. 20). 
competition. Ideally, before any such market failure appears, competition should be protected and promoted between substitute data sources and between ecosystems, so as to prevent tipping. To uphold competition by substitution in these markets and between service providers, it is necessary to utilize competition law, property law, and perhaps, new sector-specific regulations. ${ }^{50}$

An issue addressed below is whether making use of data-driven business models and network effects is anticompetitive under EU competition law. If data-driven business models plus network effects imply that monopolies are being established, should EU competition law be used to regulate network effects caused by data-driven business models? If competition between substitutes could be upheld with the help of competition law, perhaps even data-driven markets would not tip. However, for competition between substitutes to happen, the customers of cloud services need to be able to choose between different service providers and play out cloud providers against each other; they must be consumers and suppliers, so that the indirect network effect does not arise and tipping does not occur. The question is if brick-andmortar firms are able to choose between different services to the extent that competition arises. ${ }^{51}$ This depends on how the service provider contracts are drafted. If these agreements do not lock in users with platforms, enabling them to switch service provider, competition by substitution in the digital markets might appear.

\section{Service Provider Contracts}

Initially, it should be pointed out that the provision of cloud computing services is still an emerging market(s) and both the services provided and the terms and conditions for those services are evolving. While the cloud computing services may overlap, there are three main services: Infrastructure as a Service (IaaS), Platform as a Service (PaaS), and Software as a Service (SaaS). The services given are to a greater or lesser extent complex, and more or less intertwined collaborations between the cloud provider and the user imply that more or less access to the data provided by the users is required. The increased complexity may thus have consequences for data ownership and user rights. According to the Commission, it is for example often easier for a user to switch cloud service provider in the IaaS context, where the services rendered are those of data storage only. ${ }^{52}$ Moving into more complex services, such as Platform as a Service $(\mathrm{PaaS})$ and especially Software as a Service (SaaS), the difficulties of switching provider increase. So, can cloud service users in the IoT be the actors that create and uphold competition? Can they create competition by efficiently choosing between different cloud service providers? Unfortunately, this seems not to be the case.

50 Cf. the proposed P2B regulation (n 18).

51 Moreover, there is a clear difference between, on the one side, e-platforms, how they operate and what services they provide, and, on the other side, clouds and how cloud services are provided. Increasingly, however, the largest platform providers are also the largest cloud providers. This means that they create synergy effects as silo providers, since they offer both their own services that collect data, and cloud services. They may create synergies by obtaining and utilizing data from all sources. Of course, the platforms control their own data, while cloud providers control and store third party data. Indeed, the increased capacity to store data from anyone is the unique feature of the cloud. Rubinfeld and Gal (n 24). 
According to the Commission, vendor lock-in actions by cloud service providers are common and constitute a form of data localization restriction imposed by the private sector, specifically targeting data mobility across the cloud or IT systems. According to the Commission, problems may arise when users of data storage or processing services try to switch cloud service providers. ${ }^{53}$

Cloud switching can be very costly for customers (especially SMEs). It includes costs for data transport and licence fees, downtime and the need for concurrent services during a transition period, as well as the costs of network use. According to the Commission, costs may vary depending on the complexity of each switching scenario, but one example showed costs of EUR 2,700,000. Some cloud customers have reported instances where cloud services providers did not provide information regarding how to exit or switch cloud. The report also notes cases where the costs for entering the cloud were much lower than those when customers wanted to exit and port data. Thus, the cloud providers attract customers by offering low thresholds for entry, but 'lock them in' by making switching difficult and costly. This may however be a practical consequence when the user and the provider have engaged in a more complex collaboration, eg a SaaS contract, while exiting may be easier under an IaaS contract. $^{54}$

One less altruistic or practical reason for lock-ins could be to build a critical mass of users and to guarantee the flow of data created by the users to the cloud provider. This becomes apparent when analysing 'free' clouds, where some cloud providers grant access to cloud space for free, as long as they are given full access and rights to use to any and all data in the cloud. ${ }^{55}$ These agreements can also be difficult for cloud customers to exit. ${ }^{56}$

53 ibid. There seem to be other studies that also indicate some degree of lock-in effects, while indicating that this may differ, especially between services that the user pays for and free services. See, for example, Bradshaw, Millard and Walden (n 5), 15 et seq, Reed and Cunningham (n 4) 151 et seq. See also Walden and Bornico (n 22) 12, 282 et seq, indicating lock-in effects as a potential competition law problem.

54 According to the Commission, it is often easier to switch cloud service provider in the Infrastructure as a Service (IaaS) context, where the services rendered are those of data storage only. Moving into more complex services such as Platform as a Service (PaaS) and especially Software as a Service (SaaS), the difficulties of switching increase. IaaS and PaaS standards can be defined using simple interfaces, but this is often not the case with SaaS standards, which require more complex interfaces to retrieve data. European Commission (n 7) 11 et seq.

55 Bradshaw, Millard and Walden (n 5), listing among others Google Docs as a cloud, 15. See also the critique against Google for a contract clause giving Google the right to use the user's data for the cloud service Google Drive/Docs, catering mainly to persons and SMEs. For example, Whittaker (n 15). The clause read:

Your Content in our Services: When you upload or otherwise submit content to our Services, you give Google (and those we work with) a worldwide licence to use, host, store, reproduce, modify, create derivative works (such as those resulting from translations, adaptations or other changes that we make so that your content works better with our Services), communicate, publish, publicly perform, publicly display and distribute such content. The rights that you grant in this licence are for the limited purpose of operating, promoting and improving our Services, and to develop new ones. This licence continues even if you stop using our Services (for example, for a business listing that you have added to Google Maps).

56 Michael R Overly, 'Crossroads of Cybersecurity and the Law' (2017). <https://www.csoonline.com/arti cle/3217724/cloud-security/what-can-my-cloud-provider-do-with-my-data.html $>$ accessed 14 April 
One of the main issues identified by the Commission is that providers impose data localization restrictions, both contractually and technically. ${ }^{57}$ Business users lack a contractual right to port data as well as a technical ability to transmit or port certain types of data, of both personal and non-personal character. This not only concerns cloud services; platform services may also display similar problems. For example, the firms that use Amazon Marketplace generate data from when customers purchase the firms' products. While the firms know that Amazon is a competitor, or a potential competitor, they need to be on Amazon Marketplace to have any real volume of Internet traffic. Amazon will however use the data generated by the firms' sale to adapt its own business conduct, while the firms may, at best, access their own sales data and not its competitors' sales data on Amazon Marketplace. These firms can also have difficulties porting their data if they would like to exit Amazon Marketplace. ${ }^{58}$

Specific platform users, such as Uber drivers, may in certain circumstances not have access to the contact details of the customers that they serve via platforms. ${ }^{59}$ As a result, they are unable to interact with their customers outside of the platform, eg for targeted marketing initiatives or to move their customer base to another platform. Some cloud service or platform users, eg Uber drivers, are contractually limited in their ability to use data generated through a specific platform to improve their activities on other platforms. In these circumstances, data protection rules may further limit the cloud user from competing with the cloud provider.

Furthermore, firms, especially SMEs, may have major difficulties engaging cloud providers in negotiating the terms of the cloud service agreements, and solving the issues and problems they face when utilizing cloud services. The fact that these standard agreements may be skewed in favour of the cloud/platform providers can cause problems and they are difficult to negotiate. Furthermore, intermediate service customers are often less knowledgeable than their providers and that, according to the Commission, creates a certain imbalance of bargaining power, causing friction and enabling unfair behaviour on the part of internet intermediates. ${ }^{60}$

It seems that wide non-assert clauses that are not limited to the service given by the cloud service provider, together with non-tampering and non-reverse engineering clauses are, or at least until recently were, part of cloud service agreements. ${ }^{61}$ Regarding non-

2018. Indeed, a best practice clause to be used should be: 'During the term of this Agreement, Customer grants Vendor a non-transferable, non-exclusive, terminable at-will licence to use the Customer Data solely for purposes of performing the Services for Customer's benefit.' That licence should be based on the database right held by the device producer, ie the collector of data, who only stores these data with the cloud service provider. It seems that several of the larger cloud providers, eg Amazon and Google, state that they will only access customer data to develop the service given.

57 Several cloud contracts, see for example those of Amazon and Google, give the user the right to select location. Regarding the technical side, ie technical standards, interoperability and the IoT, see Lundqvist, 'Standardization' (n 47). European Commission (n 7) 11 et seq.

58 Lina M. Khan, Amazon's Antitrust Paradox, (2016) 126 Yale L.J., 780 et seq.

59 Web-based taxi-services, such as Uber, and hotel websites may have strict rules on access to customer data.

60 European Commission, Fairness in platform-to-business relations, Ref Ares(2017)5222469-25 October $2017<$ https://ec.europa.eu/info/law/better-regulation/initiatives/ares-2017-5222469_en> accessed 28 May 2018.

61 Beware the IP non-assert clause (n 9). See also Jaydip Sen (n 9), discussing the Amazon cloud service contracts, where the non-assert clause required the customer to not assert, by itself or through others, any IP claims regarding the AWS services it has used. The clause applied, without any time limit, after the 
assert clauses, the cloud users have been required to agree not to utilize their intellectual property portfolio vis-à-vis the cloud provider or the e-platform ecosystem as a whole. All firms connected to the e-ecosystem in question would be encompassed by the nonassert clause. Even though being a vertical clause, it is quite intrusive, as it might enable the system leaders or other firms in the ecosystem to leverage downstream onto markets relevant for the cloud service users, with the use of the data collected in the cloud, without risking infringement suits. Indeed, it may facilitate such conduct that Prüfer and Schottmüller warned about in their article. The cloud user, active downstream, cannot utilize its intellectual property rights against the cloud provider when the cloud provider enters the cloud users' market using knowledge gained through data. As discussed below, such non-assert covenants may be considered anticompetitive when used for leveraging under Article 102 TFEU; however, the Commission is also trying to address some of these issues through sector-specific regulations.

In conclusion, it seems that large internet intermediates (gatekeepers), often doubling as cloud providers, have been able to become the nodes in the transfer of data in their e-ecosystems through contracts with their business users. The contracts are skewed to direct all data to the gatekeepers, while the business users of their e-ecosystems have great difficulties exiting these agreements and at best have access only to their own generated data. On top of this, the contracts seem to open for the gatekeepers to enter the markets of their business users.

\section{SECTOR-SPECIFIC REGULATIONS}

To solve some of the issues discussed above, the Commission seems keen on using sector-specific regulations. However, we see no specific cloud regulation in the pipeline. Firstly, the EU Commission is introducing a platform-to-business (P2B) regulation, which targets the platform-business interface. ${ }^{62}$

The proposed $\mathrm{P} 2 \mathrm{~B}$ regulation mostly focuses on rules regarding transparency, and it seems clear that the P2B regulation will not directly cover cloud services provided by internet intermediates. Still it covers platform providers business relations with third-party sellers, eg Amazon Marketplace, and the aim, according to the Commission, is to create a levelled playing field.

The Commission seems hesitant to regulate $\mathrm{P} 2 \mathrm{~B}$ in detail. ${ }^{63}$ However, the Commission in the proposed $\mathrm{P} 2 \mathrm{~B}$ regulation has addressed the problem with

agreement had ended, and could be said to amount to a patent no-challenge clause. See also Tom Krazit (n 9). See also Richard Kempe (n 9).

62 The Commission's roadmap for the P2B stated that the overall policy objective was to ensure a fair and innovation-friendly platform economy. More specifically, the aims for a P2B, according to the Commission, should be (a) to optimize the innovation and growth potential of online platform ecosystems, by securing a predictable business environment for firms depending on platforms and thus enhancing the general level of trust of all (potential) users; (b) to limit direct negative effects of problems arising in P2B relationships; (c) to prevent, ex ante, abuse of dependencies in the platform economy; (d) to reduce burdensome compliance costs derived from legal fragmentation, which could jeopardize the functioning of the Digital Single Market, and (e) to facilitate the emergence of new online platform firms, including by reducing barriers to entry and by ensuring a level playing field. European Commission ( $\mathrm{n} 60$ ).

63 The Commission starts its proposal in a quite bold manner, stating:

$[t]$ hese online intermediation activities usually benefit from important data-driven direct and indirect network effects which tend to result in only a limited number of successful platforms per 
internet intermediates having access to more data than its customers. Article 7 of the draft P2B regulation obliges providers of online intermediation services to provide business users with a clear description of the scope, nature, and conditions of their access to and use of the business users' data.

According to the draft, the description should be proportionate and might refer to general access conditions, rather than an exhaustive identification of actual data, or categories of data, in order to enable business users to understand whether they can use the data they have created with the provider of the online intermediation service. Indeed, the provider of the online intermediation service is not obliged to give the customer (the business user) access to the data the user creates through his business on the platform, only to provide information regarding access to the data. Indirectly, the P2B proposal implies that the data created by the business that users conduct belongs to the internet intermediate, while the business user may be able to gain access through negotations of the service provider contract.

Moreover, the proposed Article 6 of the P2B regulation states that providers need to be transparent if they intend to discriminate in reference to access to data, by giving better access to affiliated firms than to the business user. Thus, the platform provider, eg Amazon, needs to provide information on whether it will give better access to the data generated on its platforms to an affiliated firm, eg itself or a subsidiary, rather than to the business user generating the data.

The proposed $\mathrm{P} 2 \mathrm{~B}$ regulation thus addresses the issue of data and who has access to it, while only creating provisions regarding transparency of the rules regarding access.

Secondly, in the proposed Data Free Flow Regulation, the European Commission has specifically addressed the issue of whether cloud users should be given the right to port non-personal data-especially vis-à-vis cloud providers. In the proposed regulation, the industry should, through self-regulation, come up with a procedure and standard technology so that data can be ported. The proposed regulation contains a call for self-regulation of the right to port data (Article 6). ${ }^{64}$ This is somewhat surprising, given the enthusiasm that the Commission has showed in early policy papers towards implementing a mandatory right to port data for business user vis-à-vis cloud providers, ${ }^{65}$ and begs the question whether the right to port should be included in some

intermediated segment of the economy. This growing intermediation of transactions through online platforms, combined with strong indirect network effects that can be fuelled by datadriven advantages by the online platforms, lead to an increased dependency of businesses on online platforms as quasi "gatekeepers" to markets and consumers. The asymmetry between the relative market strength of a small number of leading online platforms - not necessarily dominant in the sense of competition law - is exacerbated by the inherently fragmented supply-side consisting of thousands of small merchants.

However, the obligation to give business user access to term and conditions does not seem to be that intrusive. Cf. the proposed P2B regulation (n 18).

64 European Commission (n 7); European Commission (n 2).

65 European Commission, Communication from the Commission to the European Parliament, the Council, the European Economic and Social Committee and the Committee of the Regions SWD (2017) 2 Final, $\operatorname{COM}(2017) 9$ Final, 13; European Commission (n 2) 33, making reference to the works of Zech, who claimed that the right way forward was the creation of a property right to non-personal goods. Cf. Zech (n 3). 
other legislative effort by the Commission, such as the modernization of the database directive. $^{66}$

Thirdly, sector-specific regulations seem to be the preferred tool for giving competitors access to data. ${ }^{67}$ There are several specific directives and rules regarding for example public data, financial data, user-generated data originating from cars, etc., which were either recently implemented or are being proposed in the EU. To a certain extent, they provide rights to access data, or embryos of such rights, when the data is in a cloud. ${ }^{68}$ Indeed, they are embryos to the 'data commons' discussed above. They also reflect a discussion in academia to create access to data on a sector-bysector basis, rather than drawing up generally applicable principles and doctrines. ${ }^{69}$

Fourthly, as a sector-specific regulation, the General Data Protection Regulation ${ }^{70}$ (GDPR) should be added. In several aspects, it acts as a regulation for the business use of personal data, stipulating the boundaries for what should be considered competition or business on accepted terms and conditions. Indeed, what is 'competition on the merits.' ${ }^{71}$ Moreover, the GDPR includes a right to port personal data for individuals in Article 20 GDPR.

In light of the above, it seems clear that the Commission was aiming to implement several sector-specific regulations for the IoT paradigm, to create a level playing field. The underlying idea was to not only facilitate for the IoT, but also help SMEs benefit from the IoT, and to create competition. However, given the proposed P2B and Data Free Flow regulations, the question is whether the Commission actually fulfils this aim. It seems that the proposals indirectly are purporting that the gatekeepers have the ultimate right to collect and use data generated on their sites, even though business users generate the traffic. Even the data uploaded by users of a cloud service is not entirely under the control of the users, while the issue of a right to port data for business users should be decided by self-regulation. Indeed, both

66 It should be mentioned that there is a right for a person under certain circumstances to port data according to art 20 GDPR. Cf. Björn Lundqvist, 'Regulating Competition and Property in the Digital Economy - The Interface Between Data, Privacy, Intellectual Property, Fairness and Competition Law' (17 January 2018). Faculty of Law, Stockholm University Research Paper No 55. Available at SSRN: <https://ssrn. com/abstract $=3103870>$ accessed 25 March 2018.

67 Regarding public sector data, financial data and the eCall rules for the cars, see for example Lundqvist 'Standardization' (n 47).

68 Drexl mentions several legal initiatives, see Drexl (n 25). See also Lundqvist, 'Standardization' (n 47) and Lundqvist, 'Big Data, Open Data' (n 47).

69 See for example, Drexl (n 25).

70 Regulation (EU) 2016/679 of the European Parliament and of the Council of 27 April 2016 on the protection of natural persons with regard to the processing of personal data and on the free movement of such data, and repealing Directive 95/46/EC (GDPR) (n 1).

71 The German Competition Authoirty (Bundeskartellamt) is currently investigating Facebook for violating German Competition Law by violating German data protection provisions. According to the Bundeskartellamt's preliminary assessment, Facebook's terms of service are at least inappropriate and violate data protection provisions to the disadvantage of its users when Facebook can unrestrictedly collect every kind of user data from third sources, attribute it to the user's Facebook account and use it for numerous data processing activities. In view of the company's dominant position, it can also not be assumed that users effectively consent to this form of data collection and processing. Therefore, the Bundeskartellamt preliminary conclusion is that Facebook's collection and use of data from third-party sources is abusive. <https://www.bundeskartellamt.de/SharedDocs/Meldung/EN/Pressemitteilungen/ 2017/19_12_2017_Facebook.html > accessed 30 May 2018. 
these proposals seem rather watered down. It begs the questions whether or not competition law can prevent the market failures now being half-heartedly addressed in proposals to sector-specific regulations. Indeed, the problems that these sectorspecific rules seem to address yet fail to regulate are that large data holders use the data (market power) outside the notion of 'competition on the merits' to exclude, or discriminate, firms or to leverage their power so as to enter brick-and-mortar markets. This seems to be why the Commission wants to enact specific rules for P2B, access to data and right to portability, etc. However, many of the sector-specific rules proposed by the Commission fall either within the sphere of antitrust law, or fall short of the Commission's initial aim. Indeed, the need for these sector-specific regulations could be disputed.

\section{APPLICATION OF COMPETITION LAW TO CLOUD PROVIDERS}

\section{Introduction}

The conduct of e-platform intermediates and cloud providers may be considered anticompetitive for several reasons. At least three general applicable theories of antitrust harm under Article 102 TFEU could be provided: (i) contractual or technical clauses in reference to data with potential exclusionary effect, reflecting business conduct which is not competition on the merits, (ii) non-access to relevant data with exclusionary effect, or (iii) leveraging market power inherent in the data collected from users so as to exclude a competitor, which may be a user of a cloud service.

Moreover, a platform or a cloud service agreement that explicitly or implicitly stipulates rules regarding collection, sharing or division in access to data, is a collaboration agreement regarding information sharing. If the collaboration lasts for a period of time and the parties to the agreement hold some degree of market power, rules that imply exclusive access for the platform provider to data resulting from the collaboration may risk that Article 101 TFEU is triggered. Indeed, exclusivity clauses imply that the parties are agreeing not to compete in reference to data. Some guidance can be sought in the R\&D block exemption that stipulates that R\&D collaborators can not agree that only one party to the agreement should be granted exclusive access to the R\&D result (data, know-how, etc.) generated by the collaboration. Such a clause may cause the entire agreement to fall outside the block exemption (cf. Article 3 (2) R\&D block exemption). ${ }^{72}$

\section{Market Power}

It is hard to identify market power in the digital economy. Among e-platforms, Google and Facebook have been accused of holding market power due the popularity of their respective sites/ecosystems, but is that important in a future IoT setting, where the amount and quality of data might be what creates market power? Does the same methodology for establishing market power apply to cloud providers? How should the relevant market be identified? Are there double- or multi-sided markets?

72 For a longer discussion, see Björn Lundqvist, 'Competition and Data Pools' (2018) 7 Journal of European Consumer and Market Law 146-154. See also Bjorn Lundqvist, Data Collaboration, Pooling and Hoarding under Competition Law (2018). Faculty of Law, Stockholm University Research Paper No. 61. Available at SSRN: $<$ https://ssrn.com/abstract=3278578 $>$. 
Does such a definition of the relevant market promote the competition law analysis ${ }^{73}$ What about market power based only on the amount, quality and importance of data? Could such a set-up imply market power ${ }^{74}$ Indeed, some platforms access the users' data, while also providing cloud service to firms. In reference to establishing dominance, how do we quantify data amounts? What is dominance in data, when the amount of data always grows? How does this relate to multi-homing, ie where many holders have similar data? Moreover, the data held can perhaps be duplicated without unreasonable effort. Thus, data may be difficult to monopolize, with the exception of a few truly unique datasets. ${ }^{75}$ Establishing market power in reference to data in particular or the digital economy in general raises many questions.

Perhaps one way to identify the relevant market and dominance in IoT could be to connect market power in data to the related device or product markets, ie the core markets for the brick-and-mortar firms collecting data through monitors in their devices. In other words, when a provider holds data from several firms active on a specific product market, the provider could be considered to hold a similar market share in the connected upstream data market as those firms hold collectively in the product market. Moreover, firms that are active on the device market, and have a certain share of that market, may be presumed to have access to the similar share of the data originating from that market, and may thus be presumed to have a similar share of the connected data market. Perhaps the shares of a connected 'data market', could be estalblished in greater detail based on the number of users of a certain device compared with the number of users of all devices on the relevant device market.

Perhaps a similar analysis could be performed also in reference to other relevant markets where a firm has access to data from a specific service or platform, while that service or platform is active on a specific relevant market. For example if, hypothetically, a cloud provider, through its SaaS cloud provider service agreement, has access to and a right to use data from two out of three firms active on the same relevant product market, and these two independent firms have a combined market share of $\mathrm{X}$ on a relevant product market, the cloud provider could presumably be assigned the same share on the connected data market. ${ }^{76}$

The identification of dominance should also take into consideration the direct and indirect network effects and the risk of market tipping. High-quality data and better usability (predictive modelling tools), combined with a data-driven business model, may quickly create market power or even a monopoly position on the device

73 ibid. Evans, Noel and Filistrucchi et al. agree that not all digital markets are multi-sided. For an interesting analysis concluding that e-platforms are not multi-sided markets, see Newman (2014), 'Antitrust in Zeroprice Markets: Foundations', 3 et seq. <https://scholarship.law.upenn.edu/cgi/viewcontent.cgi?arti cle $=9504 \&$ context $=$ penn_law_review $>$ accessed 23 April 2018.

74 See Bundeskartellamt (2016). OECD (2016). The German and French Competition Authorities (2016), 7,14 et seq.

75 D Daniel Sokol and Roisin E Comerford, 'Does Antitrust Have a Role to Play in Regulating Big Data?' forthcoming in Cambridge Handbook of Antitrust, Intellectual Property and High Tech (Cambridge University Press 2017) <http://papers.ssrn.com/sol3/papers.cfm?abstract_id=2723693> accessed 23 November 2016.

76 A reason to break the presumption of dominance in these cases could be if the cloud provider could show that the customers use several clouds and cloud providers, ie multi-home their data. 
or brick-and-mortar market. ${ }^{77}$ Thus, holding data from several sources active on the same device market could be enough to establish market power on that data market, while also indicating that the holder of the data is a potential entrant and competitor on the device market. Indeed, the firm that best harnesses and controls the data and predictive modelling software interface can be presumed to soon acquire a larger part of the connected device market, even to become dominant, without controlling the market share normally corresponding to dominance.

The above early ideas of taking data into consideration when establishing and measuring market power are not alien to EU competition law. Similar principles regarding correlation between share of a product or device market and an upstream segment of the relevant product or service market also exists when analysing whether pharmaceutical firms are dominant regarding the R\&D poles for future drugs, or when firms conduct $\mathrm{R} \& \mathrm{D}$ for incremental innovations. ${ }^{78}$ This takes into consideration hypothetical "R\&D markets" where holders of R\&D-specific assets important for shaping future downstream markets may hold market power, or even be dominant. Indeed, data markets, though they are hypothetical, as no trade for monetary consideration takes place, should still be acknowledged as genuine markets for competition law purposes, where dominance can be identified. ${ }^{79}$

\section{Contractually or technically restricting cloud users}

As indicated above, cloud service agreements may contain potentially anticompetitive clauses that do not allow the cloud user to restrict the provider's access to the data generated by the user or its business, to terminate the agreement, port data to a competitor, or it may contain overly broad non-assert covenants. Such covenants may be in violation of Article 101 TFEU, especially if they should potential cause the exclusion of competitors. If the covenants hinder the emergence of innovative technologies, or imply the exclusion of or discrimination against certain firms by preventing their effective access to the result (ie data) of the collaboration, Article 101(1) TFEU could be triggered. ${ }^{80}$ Moreover, the covenants could indicate that the cloud provider can vertically integrate onto the core market of the cloud user without the cloud user being able to prevent it.

Clauses may, under certain circumstances, fall foul of Article 102 TFEU, because they might be considered to reflect business conduct which is not competition on the merits. However, there are no clear EU precedents in reference to competition

77 Prüfer and Schottmüller (n 20). See also the CASE AT.39740 Google Search (Shopping), 27 June 2017 and European Commission (n 7); European Commission (n 2).

78 See Horizontal Guidelines, para 119 et seq. See also Björn Lundqvist generally 'R\&D collaborations under the Competition Rules of the European Union and The Antitrust Laws of the United States' (Edward Elgar, 2015).

79 In this regard, it should be noted that even under German Competition Law, markets where trade without price is conducted can still be considered markets. Indeed, the recalcitrant attitude towards the notion of for example R\&D markets should hence have been lessened. A market without direct monetary considerations is a market for competition law purposes. Beiten Burkhardt, 'The New German Competition Law in a Nutshell', Lexology <https://www.lexology.com/library/detail.aspx?g $=535 \mathrm{~d} 2 \mathrm{bda}-4598-413 \mathrm{~d}$ 86c6-05b592b1c7b5 > accessed 30 May 2018.

80 For a longer discussion, see Björn Lundqvist, 'Competition and Data Pools' (2018) 7 Journal of European Consumer and Market Law 146-154. 
law and the digital economy. ${ }^{81}$ Some guidance may be found in older case law, originating from other industries dealing with raw material or other forms of infrastructure. According to this case law, an abuse can be committed where a dominant undertaking locks in customers by entering into long-term agreements which limit customers' choice of suppliers, making access to the customers more difficult for competitors. This is more likely when the agreement is exclusive or de facto exclusive. Historically, such cases concern distribution of electricity or supply of raw material, not data, and the cases seem somewhat dated, given that abuse was identified without the need to show anticompetitive effect. ${ }^{82}$

However, lock-in clauses, including technical lock-ins, where a cloud provider is able to refuse termination of the agreement, change of provider or porting of data on the part of the cloud user for example because data are stored in such a way that porting is impossible or excessively difficult, may be considered violating Article 102 TFEU. Such conduct can be anticompetitive, if it implies that an equal efficient competitor is excluded or prevented from competing by not being able to access potential customers. ${ }^{83} \mathrm{~A}$ cloud user providing large amounts of data and unique datasets and being locked-in by a dominant cloud provider hindering it from accessing other cloud providers, could in theory cause Article 102 TFEU to be triggered.

Non-assert clauses are another tool that may be used in cloud service agreements. Such clauses typically stipulate that the cloud user is not allowed to assert present or future patents, or other IP rights, against the cloud provider, even if that party infringes said IP rights by, for example, entering the cloud user's core brick-andmortar market. Non-assert agreements are normally not considered anticompetitive under Articles 101 or 102 TFEU; on the contrary they can be procompetitive and allow firms to avoid litigation, reduce transaction costs and solve problems arising from blocking patents. The non-assert obligation sometimes extends to third parties designated by a contracting party. ${ }^{84}$

However, non-assert clauses may unreasonably strengthen the position of the cloud provider or discourage innovation by limiting the exclusivity, particularly when the clauses are unlimited in scope or duration, or when their scope is more extensive than the 'value' that the platform or business user obtains by accessing the platform or cloud. Non-assert clauses have been under scrutiny by competition authorities in a few cases. In 2001, Microsoft was accused of having too wide non-assert clauses vis-à-vis OEMs of computers, implying that Microsoft gained access to all OEMs' hardware patents. ${ }^{85}$ In the telecom sector, there has been a discussion on whether a standard essential patent (SEP) holder may require a potential licensee to cross-

81 For cases concerning data pooling, see Lundqvist (n 46).

82 See, for example, COMP/39386 Long-term contracts in France, decision of 17 March 2010. See also, Nicolas Bessot et al. 'The EDF Long Term Contract Case: Addressing Foreclosure For The Long Term Benefit Of Industrial Customers' (2010) 2 Compet Pol News 10.

83 C-209/10_Post Danmark ECLI:EU:C:2015:651 paras 20, 22, and 26.

84 Yamane Hiroko, 'Competition Analyses of Licensing Agreements Considerations for Developing Countries under TRIPS', June 2014, Discussion paper ICTSD < https://www.ictsd.org/sites/default/ files/research/Competition\%20Analyses\%20of\%20Licensing\%20Agreements\%20Considerations\%20for \%20Developing\%20Countries\%20under\%20TRIPS.pdf> accessed 23 February 2018.

85 See 'Microsoft scraps clause in licensing contracts for PC firms', 9 March 2004, Computer Weekly, for the EU investigation in 2001, < http://www.computerweekly.com/news/2240054971/Microsoft-scraps- 
license its entire patent portfolio in return for the SEP licence, or whether that could amount to an abuse. Indeed, a non-assert requirement (in the form of a cross-licence) in those circumstances has recently been found to violate Chinese competition law in a case against Qualcomm, but has also been scrutinized by the European Commission in the past. ${ }^{86}$

Notwithstanding the above, it is clear that while both lock-in clauses, or technical lock-ins, and non-assert clauses may in certain situations be considered anticompetitive, they can perhaps more easily be found to violate unfair competition rules. The Japanese decision regarding Microsoft in 2004 is quite illustrative. Microsoft included non-assert covenants in their licences with OEMs, which suspected that Microsoft would leverage its market power in operating systems to the hardware market. The Japan Fair Trade Commission (JFTC) listed the following reason for concluding that the non-assert clause violated the unfair competition rule, Article 19 of the Japanese Competition Law (AMA): the clause was applicable not only to licensed products, but also to products sold in the future; thus, the OEMs and Microsoft could be considered potential competitors in reference to future products. Even if an OEM were to have significant relevant PC technology, its incentives to research and develop such technology would be undermined by the non-assert clause and its position weakened as a result. ${ }^{87}$

clause-in-licensing-contracts-for-PC-firms > accessed 21 March 2018. See also for the Japanese decision, Hiroko ibid. Yamane states:

The licensing agreement involving a controversial non-assertion provision (NAP) established by Microsoft Corporation (MS) with its original equipment manufacturers (OEMs) was one of the first formal JFTC cases involving IP licensing after the termination of registration-based screening control. The NAP in the contracts required that the licensees not bring any patent infringement suits against MS if Windows licensed by the company infringed patents owned by licensees on audiovisual (AV) technology. The original NAP covered a broad range of existing and future patents. Prior to the JFTC investigation, Microsoft contemplated terminating the NAP clause and did so on 31 July 2004. The modified MS contracts with OEMs from 1 August 2004 onwards did contain a NAP clause, but it covered a limited range of technologies if future Windows versions contained 'features and functions' and patents that were already implemented. A similar case relating to Microsoft's contracts with OEMs was initiated by the US Department of Justice, but was not pursued, probably due to the lack of sufficient data supporting the DOJ's allegations. The JFTC hearing decision states that: '[T] here was a high likelihood that the NAP undermined the incentives of OEMs for PC AV technology research and development'. It expresses concern that the NAP prevented and excluded competition in the market for PC AV technology and adversely affected the competitive market environment.

86 ibid. On 2 March 2015, China's National Development and Reform Commission (NDRC) issued Administrative Penalty Decision (2015) No 1, which found that Qualcomm's conduct in both the wireless SEP licence market and baseband chip market was anticompetitive. The NDRC found fault with several aspects of Qualcomm's conduct, including (1) charging royalties for expired wireless SEPs and failing to provide a patent schedule of relevant SEPs while requiring licensees to sign long-term or indefiniteterm license agreements, (2) requiring licensees to cross-license their portfolios to Qualcomm without paying value for those licences, (3) bundling SEPs and non-SEPs in its patent licences, and (4) requiring licensees to agree not to challenge the patent license agreement as a condition for receiving baseband chips. Cf. 'The Fracturing of Global FRAND Patent Licensing', 23 June 2015, William Casey, Skadden, Arps, Slate, Meagher \& Flom LLP < https://www.skadden.com/insights/publications/2015/06/the-frac turing-of-global-frand-patent-licensing $>$ accessed 23 March 2018.

87 Yamane seems quite critical and argues that Japanese antitrust rules could have been applicable, see Hiroko (n 83). 
The regular Japanese antitrust rules could perhaps have been applicable in this case. However, under unfair competition rules, the case was more straightforward. The Japanese competition authority did not have to identify relevant markets, dominance or anticompetitive effects, etc. ${ }^{88}$

Generally, lock-in clauses and non-assert agreements may violate competition law. Still, the Japanese case indicated that, for the competition authorities, using unfair competition rules may be more practical, when exclusionary effects and strategies outside the notion of competition on the merits cannot be identified. Perhaps, these kinds of clauses in platform or cloud service agreements should be addressed by the Commission, and the digital economy would benefit in this regard from a digital vertical block exemption regulation.

\section{Non-access to relevant data and leveraging market power in data to exclude an equal efficient competitor}

The more difficult issue is whether an internet intermediate doubling as a cloud provider may be considered to violate competition law by having a data advantage and leverage that advantage when competing downstream. The advantage in data may originate from a right to access and use customers' data, and such a clause may be considered anticompetitive in certain situations, eg if done in conjunction with violating a data privacy rule (German Facebook case ${ }^{89}$ ), violating sector-specific regulation such as the upcoming P2B regulation, or by exclusively hoarding data. ${ }^{90} \mathrm{~A}$ data advantage may be caused without the use of specific potentially anticompetitive clauses in the cloud provider agreement. Indeed, tech giants may have obtained data from its users, while still abiding by Article 101 TFEU. How should the structural problems of too much data in the hands of too few cloud providers or e-ecosystem leaders be handled? Or, more accurately, can competition law fix the problem when these firms use the data advantage to leverage that market power onto neighbouring markets? Indeed, this is not only interesting in reference to clouds, but also generally in reference to gatekeepers and platforms. ${ }^{91}$

The challenges of the services in the digital economy are the underlying consequences of indirect (or direct) network effects and tipping. However, to implement a data-driven business model or make use of network effects cannot in itself be anticompetitive. Antitrust harms and effects need to be identified. As case law stands today, it seems clear that anticompetitive harm focuses on exclusionary effects caused by the

88 ibid.

89 See German Competition Authority, 'Preliminary assessment in Facebook proceeding: Facebook's collection and use of data from third-party sources is abusive', 19 December 2017, <https://www.bundeskartel lamt.de/SharedDocs/Meldung/EN/Pressemitteilungen/2017/19_12_2017_Facebook.html $>$.

90 Björn Lundqvist, Portability in Datasets under Intellectual Property, Competition Law, and Blockchain (2018). Faculty of Law, Stockholm University Research Paper No. 62. Available at SSRN: https://ssrn. com/abstract $=3278580$.

91 The European Commission has begun investigations based on European competition law into Amazon's European marketplaces, in particular into Amazon's collection and use of transaction data. Also the Germany Competition Authority has initiated an investigation into the conduct of Amazon. Bundeskartellamt, Bundeskartellamt initiates abuse proceeding against Amazon, 29 November 2018, https://www.bundeskartellamt.de/SharedDocs/Publikation/EN/Pressemitteilungen/2018/29_11_ 2018_Verfahrenseinleitung_Amazon.pdf?_blob=publicationFile\&v=2, accessed 4 December 2018. 
conduct of the dominant firm, outside the realm of competition on the merits. ${ }^{92}$ The important initial issue is to identify the antitrust harm in reference to the business conduct. What is the problem to competition? Unfair behaviour does not have to be anticompetitive; this depends on the definition of competition and harm. ${ }^{93}$ Can conduct that initates network effects or tipping be considered abusive, or is it competition on the merits? That could imply going after the conduct of collecting data.

The covenant giving the cloud provider access and right to use data may not, seen individually, be considered anticompetitive. It does not cause exclusionary effects, rather exploitative effects, seen independently. As stated above, some guidance can be sought in the $R \& D$ block exemption that stipulates that $R \& D$ collaborators should not agree that only one party to the agreement is granted exclusive access to the $R \& D$ results (data, know-how, etc.) generated by the collaboration. Such a clause may cause the entire agreement to fall outside the block exemption, and be exposed to Article 101(1) TFEU (cf. Article 3 (2) R\&D block exemption). Indeed, perhaps platforms and clouds should be viewed as collaborations or data pools, rather than the property of large gatekeepers.

Within the IoT, it seems that the most likely anticompetitive behaviour of cloud providers would be discriminatory exclusionary practice, such as generally not giving access to data to service users, while leveraging dominance in the data segment downstream onto the users' brick-and-mortar product markets by giving data access to a wholly integrated firm or to an affiliated firm in its ecosystem, a proxy. Such conduct may be considered anticompetitive. Discrimination on behalf of an internet intermediate, in relation to the platform or the data collected, enabling the internet intermediate or a proxy to leverage onto the market of the cloud service user, might fall under Article 102 TFEU. The cloud provider would collect and give access to data or the result of predictive modelling to a specific firm, while refusing access to others, to enable that firm to leverage the data advantage against existing competitors. This could be seen as anticompetitive, creating discriminatory exclusion (cf. 102 c TFEU). 94

92 See C-413/14 P-Intel v Commission ECLI:EU:C:2017:632, and C-209/10 (n 82). On the exceptional circumstance doctrine, cf. ECJ, RTE, ITP \& BBC $v$ Commission, C-241/91 and C-242/91, ECLI:EU:C:1995:98 (Magill), etc.

93 See generally, Stucke and Grunes (n 21); Ezrachi and Stucke (n 21).

94 There are some similar French cases: the French Competition Authority imposed an interim measures to GDF, ordering the gas supplier to grant its competitors an access to some of the consumer data, in particular consumption data, it collected as a provider of regulated offers (on the gas market). The aim of this interim measure was to allow all suppliers to have the same level of relevant data to make competitive offers to consumers for gas and electricity (no public information or third party private database existed on households subscribing to gas contracts). French Competition Authority, Decision 14-MC-02 of 9 September 2014. Due to privacy laws, the transmission of GDF data to competitors was conditional to an approval by consumers. A significant share of the consumers refused to allow their data be transferred from GDF to competing operators. The case is discussed in the joint report by the German and French Competition Authorities (2016), 20; French Competition Authority, Decision n ${ }^{\circ} 13-\mathrm{D}-20$ of 17 December 2013, confirmed on that points by the court of appeal on 21 May 2015; A similar reasoning has also been used in some merger cases, for instance, in the EDF-Dalkia merger decision. European Commission, 'EDF/Dalkia en France', COMP/M.7137, dated 25 June 2014. 68 French Competition Authority, Décision n ${ }^{\circ}$ 14-D-06 relative à des pratiques mises en auvre par la société Cegedim dans le secteur des bases de données d'informations médicales, dated 8 July 2014. This decision has been confirmed on appeal, but is still pending in front of the Cour de Cassation (the French Supreme Court). 
To analyse possible antitrust harms in reference to not giving access to data, under Article 102 TFEU, we need to look at some specific, well-known cases. Magill, ${ }^{95}$ IMS Health, ${ }^{96}$ and Microsoft ${ }^{97}$ stipulate quite high thresholds for accessing intellectual property, trade secrets and, possibly, data held by a dominant firm. They, at least partially, belong to the exceptional circumstance doctrine and indicate that a firm may be granted access to property or even the right to continuously obtain data (eg the Microsoft case regarding the interface data used for the Windows operating system to communicate with back office servers). Indeed, the Microsoft case is interesting in this regard, since restricting access to data and, generally, interoperability is seen as a reason to use competition law to grant access to data. Further, it also relates to leveraging, since the theory of harm includes the notion that Microsoft was leveraging power from the operating systems market, where it was dominant, to the server market, by not giving access to interface information, while using that data for its own server business. ${ }^{98}$

Interoperability between systems was one of the theoretical cornerstones for testing whether Microsoft's refusal to give interface information to competing server producers could be classified as abuse. ${ }^{99}$ According to the Commission, neither reverse engineering, nor open industry standards, nor the access ensured by the communication licensing programme created in the USA, were alternative ways for Microsoft's competitors to achieve product interoperability. ${ }^{100}$ Therefore, the Commission stipulated an obligation, later upheld by EU courts, for Microsoft to supply neutral interoperability information (data) to its competitors on the server market. $^{101}$

However, when it comes to data and clouds, things are less straightforward. Each data owner may organize his data in a way which suits his or her own needs and preferences. Without an agreement or a standard on dataset vocabulary, ${ }^{102}$ an organization might create a barrier to synthesis with other data or use by others. Several

\section{C-241/91 and C-242/91 RTE, ITP \& BBC v Commission, ECLI:EU:C:1995:98.}

C-418/01, IMS Health (n 31).

T-201/04, Microsoft $v$ Commission, ECLI:EU:T:2007:289.

GC, Microsoft $v$ Commission, T-201/04, ECLI:EU:T:2007:289.

The General Court mentioned 'interoperability' 368 times, T-201/04, Microsoft ibid.

See s 5.3.1.2.3 entitled 'There are no substitutes for Microsoft providing interoperability information in the Commission's decision' in Commission decision Case COMP/C-3/37.792 Microsoft, 178-185. See also Francois Leveque, 'Innovation, Leveraging and Essential Facilities: Interoperability Licensing in the EU Microsoft Case' (March 2005) 6. Available at SSRN: <https://ssrn.com/abstract $=927900$ or http://dx.doi.org/10.2139/ssrn.927900> accessed 21 March 2018.

01 The US Aspen Skiing case is one of very few antitrust cases where an obligation to collaborate seemed to be the remedy. US Supreme Court, Aspen Skiing Co v Aspen Highlands Skiing Corp, 472 US 585 (1985). Wolfgang Kerber and Heike Schweitzer, 'Interoperability in the Digital Economy' (2017) 8 J Intell Prop, Inform Technol Elect Comm L (JIPITEC) 39-58. See also Marina Lao, 'Aspen Skiing and Trinko: Antitrust Intent and "Sacrifice”" (2005) 73 Anti L J 171 et seq.

Regarding open data in EU, there is now a general consensus to use the DCAT Application Profile for data portals and for describing public sector datasets in Europe. DCAT-AP is a specification based on the Data Catalogue vocabulary. It serves to enable cross-data portal searches for datasets and make public sector data more searchable across borders and sectors. This can be achieved by the exchange of descriptions of datasets between data portals. Many data portals in the EU have implemented DCATAP for describing datasets. Please refer to 'Who is using the DCAT-AP?' for an overview of DCAT-AP implementers. 
barriers are relevant. First, one must know what each rubric in a dataset stands for and how exactly it was determined, in order to assess its relevance and reliability. Second, barriers may arise from the way in which the data are organized, even if all parameters are known. This is especially problematic if the database includes numerous parameters or is constantly updated. ${ }^{103}$ Platform interoperability implies, instead, using the same technology standard or platform technology or language, or to make different languages, such as .NET, Java, and $\mathrm{C}++$, interoperate. Indeed, it might be difficult technically to require full interoperability for clouds and data. However, requiring interoperability is a remedy available under EU competition law.

As illustrated, the issue whether there might be abuse at hand when a firm is leveraging an advantage in data to a device market, by not giving access to said data, is complex and difficult to judge. ${ }^{104}$ Indeed, such a case is at the borderline between antitrust and industrial policy. There may be valid business reasons not to give access to data, but anticompetitive effects may appear regardless.

Nonetheless, in reference to internet intermediates, it might be useful to instate and prohibit a general form of leveraging abuse achieved by discrimination. Such leveraging abuse would require identification of the dominant firm, that, by itself or through a proxy, leverages onto a secondary (brick-and-mortar) market by giving itself or a proxy advantages through increased access to data, so that an exclusionary effect on the competitive secondary market materializes, and foreclosing an equal efficient existing competitor, by not granting access to said data.

In the EU, leveraging is considered often relevant in combination with other forms of abuses, eg tying, marginal squeezing, or refusal to supply. However, leveraging can be viewed as a broad underlying stand-alone abuse and reference can be made to cases such as Commercial Solvents, ${ }^{105}$ Telemarketing, ${ }^{106}$ TeliaSonera, ${ }^{107}$ Teléfonica, ${ }^{108}$ and Microsoft, ${ }^{109}$ where the conduct analysed is subordinate to the anticompetitive effects created by the dominant firm. ${ }^{110}$ The requirements for finding abuse under the monopoly-leveraging concept would then need a finding of two separate markets (data market and device market), a business strategy or conduct outside the notion of competition on the merits (eg discrimination in access to data) by the dominant internet intermediate on the primary data market, subsequent entry onto the (competitive) secondary market either by the internet intermediate or a proxy causing an exclusionary effect on that market by potentially foreclosing equal efficient existing competitors, and that there are no objective justifications for not giving access to the data.

A leveraging test following the steps above implies that certain features need not be present or, for that matter, identified. The service provided, in this case the cloud

103 Rubinfeld and Gal (n 24).

104 ibid.

105 C-6/73 Istituto Chemioterapico Italiano and Commercial Solvents v Commission ECLI:EU:C:1974:18.

106 C-311/84 CBEM $v$ CLT and IPB ECLI:EU:C:1985:394.

107 C-52/09 TeliaSonera Sverige ECLI:EU:C:2011:83.

108 C-295/12 P Telefónica and Telefónica de España v Commission ECLI:EU:C:2014:2062.

109 T-201/04 Microsoft $v$ Commission, Case EU:T:2007:289.

110 Thomas Hoppner, 'Duty to Treat Downstream Rivals Equally: (Merely) a Natural Remedy to Google's Monopoly Leveraging Abuse' (2017) 1 Europ Compet Regul L Rev (CoRe), 208-21. Available at SSRN: <https://ssrn.com/abstract=3040605> accessed 18 February 2018. 
service, does not need to be indispensable, and neither dominance on the secondary market nor elimination of competition on that market need be proven. These steps seem to be set in stone, yet, given that the underlying doctrine of Article 102 TFEU is uncertain, it should be admitted that the steps for a general leveraging test are, by the best estimate, ambiguous.

The remedy for a finding of abuse would be contractual and technical interoperability and data access or that the dominant firm is restricted from accessing and using cloud customers' data. Indeed, utilizing a leveraging test with the view of upholding interoperability for the IoT and access to data tends to increase competition and innovation in the digital economy, and downstream. ${ }^{111}$ Demanding a dominant firm give access for certain victims or even generally to everyone ie access for all to all data, would lessen network effects and tipping, and would intensify the competition and create efficiencies on downstream device markets. This may feel awkward for an efficiency-oriented competition lawyer, because it is akin to industry policy. However, for markets plagued with network effects and tipping, protecting data access and interoperability under competition law may be key. Perhaps data access and interoperability can uphold competition to the extent that network effects are prevented and decrease the risk that the legislator will need to create data commons through sector-specific regulations.

Notwithstanding the above, it must be acknowledged that competition law is a heavy-handed instrument. The general text of Articles 101 and 102 TFEU indicates that they are primarily to be used ex post, and any clear doctrine takes a long time to develop, given the litigation perceived as unavoidable following a decision by the Commission. Any new doctrine for the digital market would take a long time to develop. However, the Commission could draft a new block exemption for vertical agreement for the digital economy. Indeed, perhaps a data block exemption regulation should be drafted where certain conduct and collaborations are exempted for firms with market or data share below certain thresholds, while platform or cloud service agreements which allow exclusive data hoarding by a large platform provider or discriminatory access to data to the benefit of a platform provider could be prohibited should the parties to the service agreement, ie the platform provider and the user, be of certain size. However, as EU antitrust law stands today, with the exceptional circumstance doctrine. Its high market share-driven tests/barriers for showing dominance and the rather limited set of conduct types defined as 'antitrust harms', gatekeepers in the IoT era are relatively 'safe' for now. Their general business strategies based on indirect network effects and tipping will likely not be addressed under Article 102 TFEU. To capture some of the business strategies indicated above, the EU Commission should facilitate a more straightforward leveraging test based on the idea that access to data and interoperability are important values in the digital economy in data guidelines, or equivalent.

Perhaps the current maladaptation of EU antitrust law is the reason why the Commission seems so keen to introduce sector-specific regulations in this field, in reference to both unfair competition and portability of data. However, competition

111 See the earlier discussion regarding the findings by the economists Prüfer and Schottmüller and Lianos and Motchenkova. 
law has a clear use and advantage in the IoT setting and is a great tool for balancing pros and cons. A new block exemption for digital vertical agreements, with adjoining guidelines for horizontal agreement, ie data pools, and clear frames establishing what is not competition on the merits could be the key for modernizing antitrust law for the digital market, without enacting specific-sector regulations.

\section{CONCLUSION}

As discussed above, it is not uncommon that an e-platform and cloud provider has access and rights to use the data originating from its customers, even though the cloud and platform user has access only to its own data. ${ }^{12}$ The data accessible to the provider can originate from customers, suppliers, and even from competitors of the user. The provider can combine that cloud data with data obtained through its own services. Thus, the provider may be able to obtain a fuller picture of the industry because it is able to access the data from all or several participants in the industry. This would enable it not only to succeed on its own core markets, but also to leverage that data superiority so as to integrate onto the markets of its customers, the brick-and-mortar firms.

In this article, I have argued that having access to data might imply holding market power, and e-platform providers might be considered dominant when having access and rights to use to their (cloud service) customers' data. How dominance in these circumstances should be determined is a difficult nut to crack; however, it may be done by comparing the total number of users of connected devices on the regular device market with the number of device users the provider has directly or indirectly collected data from.

This article moreover addresses the issue of whether certain terms and conditions in the service agreements, inter alia non-assert clauses and lock-in clauses, may be considered in violation of competition law. In addition, the technical lock-in caused by the different standard technologies for cloud storage and transfer has been discussed. The non-assert clauses and lock-in clauses can in rare cases be considered to be in violation of Article 102 TFEU. The article also addresses the issue of whether the collection of data by the platform and cloud providers, together with such clauses, and the providers' subsequent use of the data on connected markets might be problematic and violations of either Article 102 TFEU, as abusively leveraging market power, or even in violation of Article $101 \mathrm{TFEU}$, as anticompetitive vertical and horizontal agreements excluding potential or real competitors by agreeing on exclusive data access. The article concludes that a new block exemption for vertical agreements catering to the digital economy should be developed. This may be the way to regulate abusive data use by dominant internet intermediates and cloud providers.

112 In reference to personal data, the cloud provider must gain consent to be able to access and analyse personal data from a data client. Cf. GDPR and WP29 2012. 